\title{
Fragrances by selective oxidation of long-chain alcohols
}

\author{
Alberto Villa a, Carine E-Chan-Thaw a , Marco Schiavoni a , Sebastiano Campisi a , Di Wang b, \\ Laura Prati a,* \\ a Department of Chemistry, Milan University, via Golgi 19, 20133 Milan, Italy \\ ${ }^{\mathrm{b}}$ Institute of Nanotechnology and Karlsruhe Nano Micro Facility (KNMF), Karlsruhe Institute of Technology, Hermann-von-Helmholtz-Platz 1, 76344 \\ Eggenstein-Leopoldshafen, Germany
}

\section{A R T I C L E I N F O}

Article history:

Received 31 March 2014

Accepted 16 April 2014

Published 20 June 2014

Keywords:

Aliphatic alcohol oxidation

Ruthenium catalyst

Platinum catalyst

Au modified catalyst

\begin{abstract}
A B S T R A C T
The activity and the selectivity of $\mathrm{Ru}$ and $\mathrm{Pt}$ based carbon catalysts in the selective oxidation of long-chain aliphatic alcohols (C8, C10, C12) have been investigated. Ru/AC and Pt/AC always showed good initial activity, however deactivation phenomena rapidly depressed the catalytic performance of the catalysts. These phenomena can be limited by modification of $\mathrm{Ru} / \mathrm{AC}$ and $\mathrm{Pt} / \mathrm{AC}$ with $\mathrm{Au}$ improving the durability of the catalyst. $\mathrm{Ru} / \mathrm{AC}$ and $\mathrm{AuRu} / \mathrm{AC}$ showed good selectivity to the corresponding aldehyde ( $>95 \%)$ making these catalysts promising for fragrances manufacturing. The advantage in using Au modified catalyst lies on the easier regeneration procedure compared to the one necessary for Ru/AC. Pt / AC and AuPt/AC showed a lower selectivity to aldehyde promoting the formation of the acid and the ester formation respectively. The addition of water in the solvent system speeds up the reaction rate but drastically decreased the selectivity to aldehyde especially in the case of Pt based catalysts.
\end{abstract}

(C) 2014, Dalian Institute of Chemical Physics, Chinese Academy of Sciences. Published by Elsevier B.V. All rights reserved.

\section{Introduction}

Aldehydes with a linear aliphatic carbon chain have desirable olfactory properties and they found several industrial applications in the production of perfumes and essences [1-4]. For example, $n$-octanal (present in lemon oil), $n$-capraldehyde (C10) (present in sweet orange, lemongrass, coriander), and $n$-dodecanal (present in oils and lemon) are so effective that they markedly affect the feature of the perfume to which they are incorporated [5]. These aldehydes can be found in natural products such as essential oils and fruits of plants, but the growing market demand has made the synthetic route increasingly attractive. The selective oxidation of the corresponding long chain alcohols constitutes a highly convenient alternative [5]. For environmental and economic reasons, replacing stoichiometric oxidants with heterogeneous catalysts and molecu- lar oxygen, as a green and selective oxidant, is very desirable [1-4]. Many heterogeneous catalytic systems have been reported for the selective oxidation of aliphatic alcohols. However, the most part of the catalysts, in particular those based on $\mathrm{Au}$ [6-9], Pt [10-13], Pd [11,14], and Ru [15-19] have been only tested in the base free oxidation of 1-octanol, as representative of the non-activated long chain aliphatic primary alcohol.

$\mathrm{Ru}$ based catalysts seem to be the most promising for the typical high selectivity to carbonyl compounds instead of carboxylic ones. Different groups showed, for example, that $\mathrm{Ru}$ nanoparticles supported on hydroxyapatite $[15,16]$ or graphene nanosheets [19] are very efficient in the 1-octanol oxidation with a selectivity to aldehyde of $>95 \%$. We recently showed that it is possible to enhance the catalytic performance of Ru catalysts by alloying Au nanoparticles, maintaining a high

* Corresponding author. Tel: +39-0250314357; Fax: +39-0250314405; E-mail: Laura.Prati@unimi.it 
selectivity to octanal (>99\%) [18].

Conversely, only a few examples of selective catalytic oxidation concerning long aliphatic chain alcohol ( $>$ C10) have been reported [5], and very low yields to the desired aldehyde are usually achieved. For example, a 10\% commercial Ru/AC catalyst was able to convert 1 -decanol using toluene $/ \mathrm{H}_{2} \mathrm{O}$ as solvent $\left(90{ }^{\circ} \mathrm{C}, 1 \mathrm{~atm} \mathrm{O}_{2}\right.$ ) with decanoic acid as main product (59\%) [20]. Musawir et al. [21] reported the oxidation of 1 dodecanol in toluene at $100{ }^{\circ} \mathrm{C}$ using a Ru-Co binary oxide with the addition of 2,6-di-tert-butyl-p-cresol, yielding to a maximum conversion of $52 \%$ with a selectivity of $83 \%$ to aldehyde. Mori et al. [22] reported the oxidation of 1-dodecanol to 1-dodecanoic acid without any formation of the corresponding aldehyde using RuHAP- $\gamma-\mathrm{Fe}_{2} \mathrm{O}_{3}$ and toluene as solvent ( $90{ }^{\circ} \mathrm{C}, \mathrm{O}_{2}$ flow). Therefore, it appears clear that the development of an efficient catalytic system able to oxidize long chain aliphatic alcohols to the corresponding aldehyde is still challenging.

In this paper, different aliphatic alcohols (1-octanol, 1-decanol, and 1-dodecanol) have been considered with the aim to correlate the length of the chain to the activity, selectivity and stability in the oxidation reaction. The effect of the nature of the metal (Ru and Pt) as well as the beneficial effect of $\mathrm{Au}$ addition, already evidenced in the 1-octanol and glycerol oxidation, have been investigated. The effect of solvent was also studied. Indeed, it has been recently shown that the presence of water is particularly beneficial and is able to speed up the reaction up in the case of $\mathrm{Pt} / \mathrm{AC}$ in the selective oxidation of 1-octanol [13].

\section{Experimental}

\subsection{Materials}

$\mathrm{NaAuCl}_{4} \cdot 2 \mathrm{H}_{2} \mathrm{O}$ and $\mathrm{K}_{2} \mathrm{PtCl}_{4}$ were obtained from Aldrich (99.99\% purity), $\mathrm{NaBH}_{4}$ of purity $>96 \%$ from Fluka and polyvinylalcohol (PVA) $\left(M_{\mathrm{w}}=13000-23000,87 \%-89 \%\right.$ hydrolyzed) from Aldrich were used. Gaseous oxygen and hydrogen from SIAD was 99.99\% pure. Stock aqueous solutions of PVA (1\%, wt/wt) and $\mathrm{NaBH}_{4}(0.1 \mathrm{~mol} / \mathrm{L})$ were prepared. 1 -octanol, 1-decanol and 1-dodecanol (99.5\%) and all the intermediates were from sigma Aldrich. Commercial Ru/AC (Escat 40, 5\%wt) was from Engelhard.

\subsection{Catalyst preparation}

\subsubsection{Monometallic catalyst}

$\mathrm{Au} / \mathrm{AC}$ : solid $\mathrm{NaAuCl}_{4} \cdot 2 \mathrm{H}_{2} \mathrm{O}(0.051 \mathrm{mmol})$ and PVA (Au/PVA $=1: 1 \mathrm{wt} / \mathrm{wt}$ ) solution were added to $100 \mathrm{~mL}$ of $\mathrm{H}_{2} \mathrm{O}$. The solution was stirred for $3 \mathrm{~min}, 0.1 \mathrm{~mol} / \mathrm{L} \mathrm{NaBH}_{4}\left(\mathrm{Au} / \mathrm{NaBH}_{4}=1: 4\right.$ $\mathrm{mol} / \mathrm{mol}$ ) solution was added to the yellow solution under vigorous magnetic stirring. A ruby red $\mathrm{Au}(0)$ sol was immediately formed. Within few minutes from their generation, the colloids (acidified at $\mathrm{pH} \mathrm{2,} \mathrm{by} \mathrm{sulphuric} \mathrm{acid)} \mathrm{were} \mathrm{immobilized} \mathrm{by}$ adding the support under vigorous stirring. The amount of support was calculated as having a gold loading of $1 \mathrm{wt} \%$. The catalysts were filtered, thoroughly with distilled water (neutral mother liquors) and dried at $80^{\circ} \mathrm{C}$ for $4 \mathrm{~h}$.
Pt/AC: $\mathrm{K}_{2} \mathrm{PtCl}_{4}$ (Au:0.051 mmol) was dissolved in $100 \mathrm{~mL}$ of $\mathrm{H}_{2} \mathrm{O}$, and PVA was added (Pt/PVA $=1: 1 \mathrm{wt} / \mathrm{wt}$ ). The solution was stirred for $3 \mathrm{~min}$, after which $0.1 \mathrm{~mol} / \mathrm{L} \mathrm{NaBH}_{4}\left(\mathrm{Pt} / \mathrm{NaBH}_{4}\right.$ $=1: 16 \mathrm{~mol} / \mathrm{mol}$ ) was added under vigorous magnetic stirring. The light-grey $\operatorname{Pt}(0)$ sol was formed after $30 \mathrm{~min}$. Within $1 \mathrm{~h}$ of sol generation, the Pt sol was immobilized by adding the support (acidified to pH 2 by sulphuric acid) under vigorous stirring. The amount of support was calculated as having a $\mathrm{Pt}$ loading of $1 \mathrm{wt} \%$. After $2 \mathrm{~h}$, the slurry was filtered and the catalyst washed thoroughly with distilled water (neutral mother liquors) and dried at $80^{\circ} \mathrm{C}$ for $4 \mathrm{~h}$.

\subsubsection{Bimetallic catalyst}

$\mathrm{AuRu} / \mathrm{AC}$ : Bimetallic system was prepared as reported in [18], immobilizing PVA stabilized AuNPs on commercial Ru/AC (i.e. $\mathrm{AuRu} / \mathrm{AC}$ ). Preparation of PVA stabilized AuNPs: solid $\mathrm{NaAuCl}_{4} \cdot 2 \mathrm{H}_{2} \mathrm{O}(0.051 \mathrm{mmol})$ and PVA (Au/PVA $\left.=1: 1 \mathrm{wt} / \mathrm{wt}\right)$ solution were added to $100 \mathrm{~mL}$ of $\mathrm{H}_{2} \mathrm{O}$. After $3 \mathrm{~min}, 0.1 \mathrm{M} \mathrm{NaBH}_{4}$ $\left(\mathrm{Au} / \mathrm{NaBH}_{4}=1: 4 \mathrm{~mol} / \mathrm{mol}\right)$ solution was added to the yellow solution under vigorous magnetic stirring. A ruby red Au(0) sol was immediately formed. Within few minutes from their generation, the colloid (acidified at $\mathrm{pH} 2$, by sulphuric acid) was immobilized by adding the $\mathrm{Ru} / \mathrm{AC}$ under vigorous stirring. The amount of support was calculated in order to obtain a final metal loading of $1 \mathrm{wt} \%$ (on the basis of quantitative loading of the metal on the support) and $\mathrm{Au} / \mathrm{Ru}$ ratio of $1 / 10 \mathrm{~mol} / \mathrm{mol}$. The catalyst was filtered, washed on the filter and dried at 80 ${ }^{\circ} \mathrm{C}$ for $4 \mathrm{~h}$.

AuPt/AC: $\mathrm{NaAuCl}_{4} \cdot 2 \mathrm{H}_{2} \mathrm{O}(\mathrm{Au}: 0.031 \mathrm{mmol}$ ) was dissolved in $60 \mathrm{~mL}$ of $\mathrm{H}_{2} \mathrm{O}$, and PVA ( $1 \mathrm{wt} \%$ ) was added (Au/PVA $=1: 1$ wt/wt). The yellow solution was stirred for $3 \mathrm{~min}$, after which $0.1 \mathrm{~mol} / \mathrm{L} \mathrm{NaBH}_{4}\left(\mathrm{Au} / \mathrm{NaBH}_{4}=1: 4 \mathrm{~mol} / \mathrm{mol}\right)$ was added under vigorous magnetic stirring. The ruby-red $\mathrm{Au}(0)$ sol was formed immediately. Within a few minutes of sol generation, the gold sol was immobilized by adding the support (acidified to $\mathrm{pH}=2$ by sulphuric acid) under vigorous stirring. The amount of support was calculated as having a gold loading of $0.60 \mathrm{wt} \%$. After $2 \mathrm{~h}$, the slurry was filtered and the catalyst washed thoroughly with distilled water (neutral mother liquors). The $\mathrm{Au} /$ support was dispersed in $40 \mathrm{~mL}$ of water, with $\mathrm{K}_{2} \mathrm{PtCl}_{4}$ (Pt: $0.02 \mathrm{mmol}$ ) and PVA solution (Pt/PVA = 1:1 wt/wt) added. $\mathrm{H}_{2}$ was bubbled (50 $\mathrm{mL} / \mathrm{min}$ ) under atmospheric pressure and room temperature for $2 \mathrm{~h}$. After an additional $18 \mathrm{~h}$, the slurry was filtered and the catalyst washed thoroughly with distilled water, and dried at $80^{\circ} \mathrm{C}$ for $4 \mathrm{~h}$. The total metal loading was $1 \mathrm{wt} \%$.

\subsection{Characterisation}

The Au@(Ru/AC) catalyst was examined in a FEI Titan 80-300 electron microscope equipped with CEOS image spherical aberration corrector, Fischione model 3000 HAADF STEM detector and EDAX SUTW EDX detector. The microscope was operated at an accelerating voltage of $300 \mathrm{kV}$ in TEM mode for HRTEM and in STEM mode for STEM and EDX spectrum imaging. The Pt@(Au/AC) catalyst was examined in a Philips CM200 FEG microscope equipped with an EDAX DX4 analyzer for EDX spectra acquisition. The electron microscope was operated at 
an accelerating voltage of $200 \mathrm{kV}$. The actual metal content was checked by ICP analysis on a Jobin Yvon JY24.

\subsection{Oxidation of alcohols}

Reactions were carried out in a $30 \mathrm{~mL}$ glass reactor equipped with a thermostat and an electronically controlled magnetic stirrer connected to a $5000 \mathrm{~mL}$ reservoir charged with oxygen (300 kPa). The oxygen uptake was followed by a mass-flow controller connected to a PC through an A/D board, plotting a flow time diagram. Alcohol oxidation: alcohol and the catalyst (alcohol $/$ total metal $=100 \mathrm{~mol} / \mathrm{mol}$ ) were mixed in the solvent (toluene, dioxane or dioxane water 70/30 vol/vol) (alcohol $0.6 \mathrm{~mol} / \mathrm{L}$; total volume, $10 \mathrm{~mL}$ ). The reactor was pressurized at $200 \mathrm{kPa}$ of oxygen and set to $100{ }^{\circ} \mathrm{C}$. The reaction was initiated by stirring. Periodic removal of samples from the reactor was performed. Recycling tests were carried out under the same conditions (alcohol/metal: $100 \mathrm{~mol} / \mathrm{mol}, 100{ }^{\circ} \mathrm{C}, 2$ atm $\mathrm{O}_{2}, 1250 \mathrm{r} / \mathrm{min}$, alcohol $0.6 \mathrm{~mol} / \mathrm{L}$ ). Three different methodologies were adopted. In the first, the catalyst was recycled in the subsequent run after filtration without any further treatment. In the second one, the catalyst was thoroughly washed with toluene before the further reaction. In alternative, the catalyst was regenerated in $\mathrm{H}_{2}$ at $300^{\circ} \mathrm{C}$ for $3 \mathrm{~h}$.

Identification and analysis of the products were done by comparison with the authentic samples by GC using a HP $7820 \mathrm{~A}$ gas chromatograph equipped with a capillary column (HP-5 $30 \mathrm{~m}$ x $0.32 \mathrm{~mm}, 0.25 \mu \mathrm{m}$ Film, by Agilent Technologies) and TCD detector. Quantification of the reaction products was done by the external calibration method.

\section{Results and discussion}

$\mathrm{Au}$ and Pt monometallic catalysts were synthesized by a previously described procedure of sol immobilization using polyvinyl alcohol as protective agent [11,23,24], whereas a commercial Ru/AC catalyst (Escat 40) was used. AuPt/AC was prepared using a two-step procedure that was demonstrated to produce AuPt alloyed NPs of similar composition with multiply twinned structure highly dispersed on activated carbon [11] (Fig. 1).

For the synthesis of AuRu/AC, commercial Ru/AC (Escat 40)

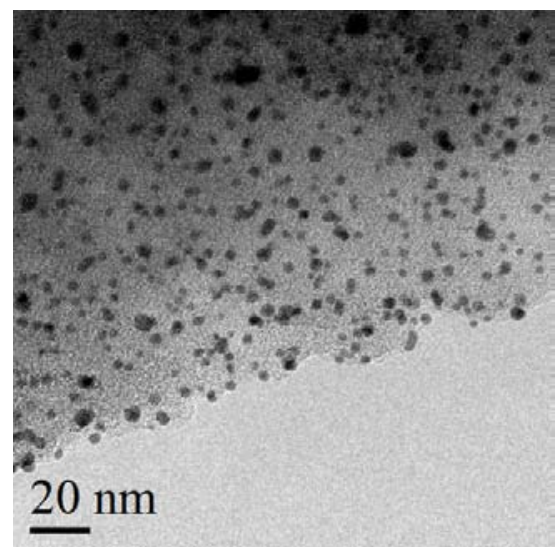

Fig. 1. Electron micrographs of AuPt/AC catalyst.

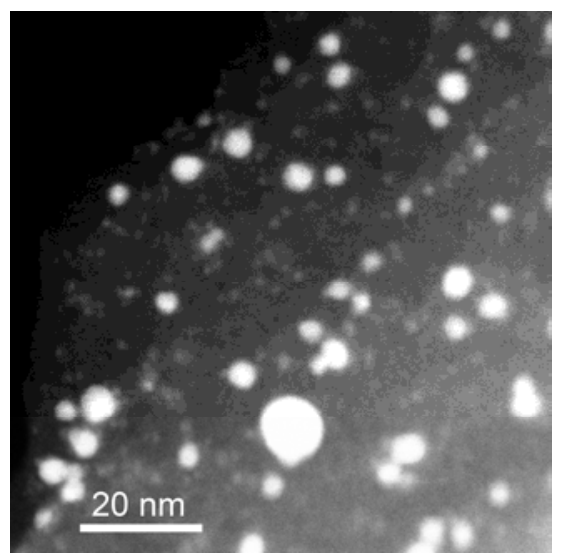

Fig. 2. Electron micrographs of $\mathrm{AuRu} / \mathrm{AC}$ catalyst.

was used as starting material where Ru NPs act as seed for the subsequent deposition of Au PVA protected nanoparticles following the procedure report in ref [18]. In this case, however, a very inhomogeneous distribution, with the segregation of small particles principally composed by $\mathrm{Ru}$ and larger bimetallic particles enrich of Au have been obtained (Fig. 2).

All the catalysts are composed by small nanoparticles with an average diameter of 3-3.6 $\mathrm{nm}$ except for AuRu where slightly bigger particles of $4.2 \mathrm{~nm}$ are present (Table 1 ).

The catalysts were first tested in the oxidation of 1-octanol, 1-decanol, and 1-dodecanol using toluene as solvent (0.6 mol/L in toluene, metal/alcohol ratio $1 / 100(\mathrm{~mol} / \mathrm{mol}), T=100{ }^{\circ} \mathrm{C}$, $p\left(\mathrm{O}_{2}\right)=2 \mathrm{kPa}$ ) (Table 2). Table 2 reported the initial activity of the catalysts, expressed as moles of alcohol converted per hour per mol of metal and calculated after 15 min reaction, and the conversion after $12 \mathrm{~h}$. On the base of the initial activity, as expected, it can be observed that increasing the length of the chain, from C8 to C12 the reactivity of the alcohol decreases (Table 2), and $\mathrm{Au} / \mathrm{AC}$ did not show any significant activity.

$\mathrm{Pt} / \mathrm{C}$ was superior than $\mathrm{Ru} / \mathrm{AC}$, in the oxidation of 1-octanol, showing an activity of 141 with respect to $114\left(\mathrm{~mol} \mathrm{~mol}^{-1} \mathrm{~h}^{-1}\right)$, reaching a conversion of $75 \%$ and $55 \%$ after $12 \mathrm{~h}$, respectively. On the contrary $\mathrm{Ru} / \mathrm{AC}$ resulted more active than $\mathrm{Pt} / \mathrm{AC}$ in the oxidation of 1-decanol and 1-dodecanol, with an activity of 84 and $68\left(\mathrm{~mol} \mathrm{~mol}^{-1} \mathrm{~h}^{-1}\right)$ in the $\mathrm{C} 10$ oxidation and 65 and 46 (mol $\mathrm{mol}^{-1} \mathrm{~h}^{-1}$ ) in the $\mathrm{C} 12$ oxidation, respectively. In other words, the activity of $\mathrm{Ru}$ catalysts appeared less sensitive to the increasing of the chain length.

In terms of selectivity, $\mathrm{Ru} / \mathrm{AC}$ always exhibited a very high selectivity to aldehydes (>95\%), whereas Pt/AC promoted the formation of carboxylic acids and esters (Table 2). In particular, the amount of carboxylic acid increases with the increasing of the length of the chain, becoming the main product in the oxi-

Table 1

Statistical median and standard deviation of particle size analysis.

\begin{tabular}{lcc}
\hline Catalyst & Statistical median $(\mathrm{nm})$ & Standard deviation $\sigma$ \\
\hline $\mathrm{Au} / \mathrm{AC}$ & 3.6 & 1.2 \\
$\mathrm{Ru} / \mathrm{AC}$ & 3.0 & 0.9 \\
$\mathrm{Pt} / \mathrm{AC}$ & 3.3 & 1.2 \\
$\mathrm{AuPt} / \mathrm{AC}$ & 3.2 & 1.1 \\
$\mathrm{AuRu} / \mathrm{AC}$ & 4.2 & 1.4 \\
\hline
\end{tabular}


Table 2

Alcohols oxidation in toluene.

\begin{tabular}{|c|c|c|c|c|c|c|}
\hline \multirow[b]{2}{*}{ Catalyst } & \multirow[b]{2}{*}{ Substrate } & \multirow{2}{*}{$\begin{array}{c}\text { Activity } \\
\text { (mol mol}^{-1} \\
\left.\mathrm{~h}^{-1}\right)\end{array}$} & \multirow{2}{*}{$\begin{array}{c}\text { Conver- } \\
\text { sion }^{\mathrm{b}} \\
(\%)\end{array}$} & \multicolumn{3}{|c|}{ Selectivity $^{\mathrm{c}}(\%)$} \\
\hline & & & & Aldehyde & Acid & Est \\
\hline$\overline{\mathrm{Au} / \mathrm{AC}}$ & 1-octanol & 3 & 5 & - & - & - \\
\hline $\mathrm{Ru} / \mathrm{AC}$ & 1-octanol & 114 & 55 & $>99$ & - & - \\
\hline $\mathrm{AuRu} / \mathrm{AC}$ & 1-octanol & 63 & 66 & $>99$ & - & - \\
\hline $\mathrm{Pt} / \mathrm{AC}$ & 1-octanol & 141 & 75 & 47 & 25 & 26 \\
\hline $\mathrm{AuPt} / \mathrm{AC}$ & 1-octanol & 127 & 85 & 50 & 10 & 38 \\
\hline $\mathrm{Au} / \mathrm{AC}$ & 1-decanol & 1 & 3 & - & - & - \\
\hline $\mathrm{Ru} / \mathrm{AC}$ & 1-decanol & 84 & 46 & 94 & 6 & - \\
\hline $\mathrm{AuRu} / \mathrm{AC}$ & 1-dece & 59 & 68 & 98 & - & 1 \\
\hline $\mathrm{Pt} / \mathrm{AC}$ & 1-decanol & 68 & 70 & 40 & 50 & 5 \\
\hline AuPt/AC & 1-decanol & 28 & 81 & 52 & - & 48 \\
\hline $\mathrm{Au} / \mathrm{AC}$ & 1-dodecanol & 2 & 4 & - & - & - \\
\hline $\mathrm{Ru} / \mathrm{AC}$ & 1-dodecanol & 65 & 33 & 96 & - & - \\
\hline $\mathrm{AuRu} / \mathrm{AC}$ & 1-dodecanol & 61 & 49 & 98 & - & 一 \\
\hline $\mathrm{Pt} / \mathrm{AC}$ & 1-dodecanol & 46 & 56 & 36 & 54 & 7 \\
\hline AuPt/AC & 1-dodecanol & 25 & 62 & 45 & 5 & 48 \\
\hline
\end{tabular}

Reaction conditions: $0.6 \mathrm{~mol} / \mathrm{L}$, metal/alcohol ratio $1 / 100$ (mol/mol), $T$ $=100^{\circ} \mathrm{C}, p\left(\mathrm{O}_{2}\right)=200 \mathrm{kPa}$.

a Mol of alcohol converted per hour per mol of metal, calculated after 15 min reaction.

b Conversion after $12 \mathrm{~h}$ of reaction.

c Selectivity at $60 \%$ of conversion.

dation of 1-decanol (50\%) and 1-dodecanol (54\%).

The addition of $\mathrm{Au}$ to $\mathrm{Ru}$ or Pt has a detrimental effect on the initial activity, resulting, for 1-octanol, in an activity loss of 10 and $50 \%$ for $\mathrm{AuPt} / \mathrm{AC}$ and $\mathrm{AuRu} / \mathrm{AC}$, respectively, compared to the corresponding monometallic. However, two important differences have to be highlighted.

The first is that the detrimental effect of $\mathrm{Au}$ drastically increased with the chain length in the case of Pt/AC, reaching a $60 \%$ of initial activity loss in the case of decanol (Table 2). On the contrary, the loss of activity for Ru/AC decreased by increasing the chain length. Indeed, the initial activity for $\mathrm{Au}-$ $\mathrm{Ru} / \mathrm{AC}$ was almost the same for 1-octanol $\left(63 \mathrm{~h}^{-1}\right)$, decanol (59 $\left.\mathrm{h}^{-1}\right)$ and dodecanol $\left(61 \mathrm{~h}^{-1}\right)$.

The second interesting aspect lies on the reaction profiles. In all the cases the addition of $\mathrm{Au}$ has a beneficial effect on the durability of the catalyst reactivity. Figure 3 represents the

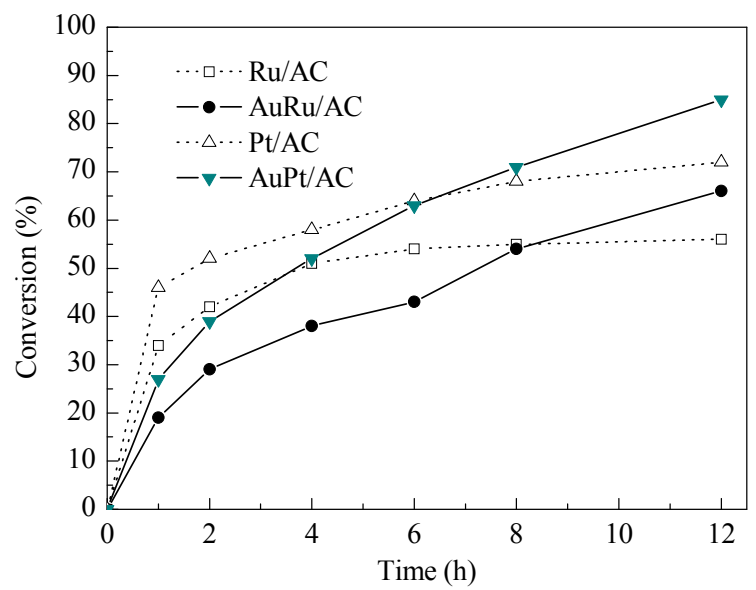

Fig. 3. Reaction profiles of carbon based catalysts in the oxidation of 1-octanol in toluene.

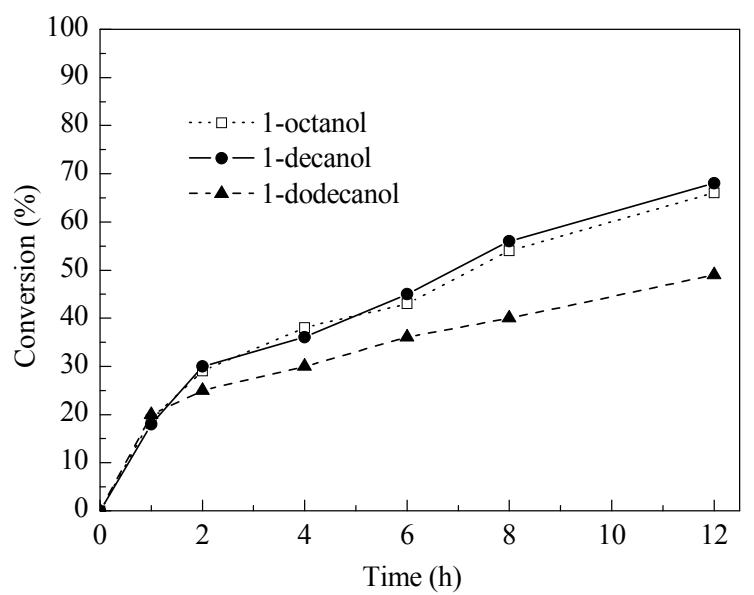

Fig. 4. Reaction profiles of $\mathrm{AuRu} / \mathrm{AC}$ in the oxidation of 1-octanol, 1-decanol and 1-dodecanol in toluene.

reaction profiles for the four catalysts in the oxidation of 1-octanol. Moreover, it should be noted that the effect of the length of the $\mathrm{C}$-chain resulted almost negligible for $\mathrm{AuRu} / \mathrm{AC}$ (Fig. 4), whereas is more pronounced for AuPt/AC (Fig. 5).

Of particular importance for the present application is the fact that the addition of $\mathrm{Au}$ to $\mathrm{Ru} / \mathrm{AC}$ does not alter significantly the selectivity to aldehyde ( $>95 \%$ ) for all the three substrates. On the contrary, the addition of Au to Pt considerably increases the amount of ester formed at the expense of the acid. This difference is particularly evidenced in the oxidation of 1-decanol and 1-dodecanol. Using Pt/AC, the acid is the main product (50\%) whereas using AuPt/AC the acid is almost absent and the ester becomes the main product (50\%) (Table 2). The promotion of ester formation operated by $\mathrm{Au}$ has been already reported in liquid phase oxidation. Hutchings' group [25] showed that the addition of $\mathrm{Au}$ to $\mathrm{Pd} / \mathrm{TiO}_{2}$ enhanced the formation of methyl lactate during the oxidative esterification of 1,2-propanediol in methanol. More recently, Haruta et al. [7] showed that $\mathrm{Au}$ catalyst promotes the formation of octyl octanoate during the 1-octanol oxidation compared to Pd catalyst. Moreover, the same authors reported that the support plays a fundamental role in improving the selectivity, obtaining $91 \%$ of

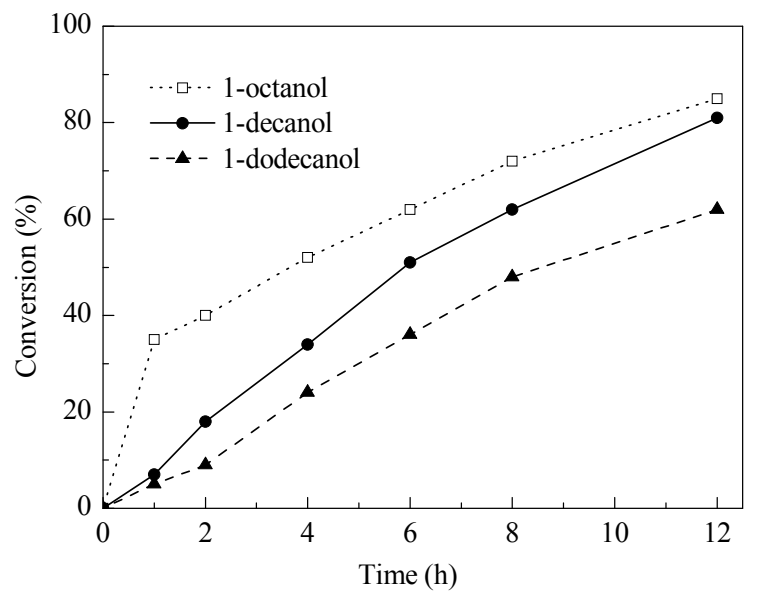

Fig. 5. Reaction profiles of $\mathrm{AuPt} / \mathrm{AC}$ in the oxidation of 1-octanol, 1-decanol and 1-dodecanol in toluene. 
Table 3

Effect of solvent in 1-octanol oxidation.

\begin{tabular}{|c|c|c|c|c|c|c|}
\hline \multirow{2}{*}{ Catalyst } & \multirow{2}{*}{ Solvent } & \multirow{2}{*}{$\begin{array}{c}\text { Activity a } \\
\left(\mathrm{mol} \mathrm{mol}^{-1} \mathrm{~h}^{-1}\right)\end{array}$} & \multirow{2}{*}{$\begin{array}{c}\text { Conversion (\%) } \\
\text { after } 12 \mathrm{~h}\end{array}$} & \multicolumn{3}{|c|}{ Selectivityc (\%) } \\
\hline & & & & Aldehyde & Acid & Ester \\
\hline $\mathrm{Ru} / \mathrm{AC}$ & toluene & 114 & 59 & $>99$ & - & - \\
\hline $\mathrm{AuRu} / \mathrm{AC}$ & toluene & 63 & 66 & $>99$ & - & - \\
\hline $\mathrm{Pt} / \mathrm{AC}$ & toluene & 141 & 72 & 47 & 25 & 26 \\
\hline $\mathrm{AuPt} / \mathrm{AC}$ & toluene & 87 & 85 & 60 & 10 & 28 \\
\hline $\mathrm{Ru} / \mathrm{AC}$ & dioxane & 24 & 33 & 90 & 2 & 3 \\
\hline $\mathrm{AuRu} / \mathrm{AC}$ & dioxane & 26 & 44 & 91 & 1 & 5 \\
\hline $\mathrm{Pt} / \mathrm{AC}$ & dioxane & 127 & 86 & 45 & 53 & 2 \\
\hline $\mathrm{AuPt} / \mathrm{AC}$ & dioxane & 115 & 91 & 84 & - & 9 \\
\hline $\mathrm{Ru} / \mathrm{AC}$ & dioxane/water $7 / 3$ & 48 & 39 & 82 & 16 & 3 \\
\hline $\mathrm{AuRu} / \mathrm{AC}$ & dioxane/water $7 / 3$ & 34 & 52 & 84 & 12 & 4 \\
\hline $\mathrm{Pt} / \mathrm{AC}$ & dioxane/water $7 / 3$ & 197 & $96^{b}$ & 32 & 67 & 1 \\
\hline $\mathrm{AuPt} / \mathrm{AC}$ & dioxane/water $7 / 3$ & 243 & $97 \mathrm{~b}$ & 52 & 22 & 15 \\
\hline
\end{tabular}

Reaction conditions: $0.6 \mathrm{~mol} / \mathrm{L}$, metal/alcohol ratio $1 / 100(\mathrm{~mol} / \mathrm{mol}), T=100^{\circ} \mathrm{C}, p\left(\mathrm{O}_{2}\right)=200 \mathrm{kPa}$.

a Mol of alcohol converted per hour per mol of metal, calculated after 15 min reaction.

b Conversion after $4 \mathrm{~h}$ of reaction.

c Selectivity at $60 \%$ of conversion.

octyl octanoate using $\mathrm{CeO}_{2}$ supported Au nanoparticles.

In order to increase the activity of the tested catalysts, we also investigated the possible solvent effect. It is indeed reported that the activity of Pt/AC in the 1-octanol oxidation can be increased of one order of magnitude using a 7:3 dioxane/water solvent system [13]. The substitution of toluene with dioxane as solvent negatively affects the activity except the one of AuPt/AC (Table 3).

In the case of Ru based catalysts, a negative effect was also observed in the selectivity toward aldehyde that decreased from $99 \%$ to $90 \%-91 \%$. Pt/AC showed almost the same selectivity to aldehyde as using toluene as solvent (about $45 \%$ ), but the octanoic acid amount is increased at the expense of the one of ester. AuPt/AC showed a peculiar behavior compared to the other three catalysts. Indeed, the use of dioxane as solvent leads not only to an increase of the activity $(115$ and $87 \mathrm{~mol}$ $\mathrm{mol}^{-1} \mathrm{~h}^{-1}$ for dioxane and toluene, respectively) but also to the selectivity to aldehyde ( $84 \%$ and $60 \%$ for dioxane and toluene, respectively) (Table 3).

The addition of water promotes as expected the activity of Pt and also the one of AuPt catalysts (Table 3). Indeed, the two catalysts were able to fully oxidize 1 -octanol in only $4 \mathrm{~h}$ whereas, using toluene as the solvent, $12 \mathrm{~h}$ of reaction were required to reach $90 \%$ conversion. Besson et al. [13] ascribed the beneficial effect of water in 1-octanol oxidation using Pt/AC to the modification of the affinity of the substrate for the hydrophobic catalyst surface of carbon, favouring the adsorption of the alcohol and the desorption of the carbonyl compound. In addition, water, a weak base, may assist the first step of the reaction, i.e. the H-abstraction from the alcohol during the dissociative chemisorption of the alcohol molecule on the catalyst surface $[10,13]$. The beneficial effect of water addition was also observed in the case of Ru catalysts. This positive effect was stronger in the case of $\mathrm{Pt} / \mathrm{AC}$ than in $\mathrm{Au} / \mathrm{Pt} / \mathrm{AC}$. However, we also observed a drastic effect on the selectivity, with the formation of a higher amount of carboxylic acid (Table 3). The possible explanation is that water promotes the hydration of the aldehyde to geminal diol thus improving the subsequent rapid dehydrogenation to acid [1,2].

Summing up the results, in view of a possible application of a catalytic route for fragrance syntheses from the corresponding alcohol, Ru based catalysts appeared the most promising catalytic systems. The enhanced stability obtained by the addition of $\mathrm{Au}$ to $\mathrm{Ru} / \mathrm{AC}$ can be also fruitfully valorized in the catalyst recycling. We then performed recycling test on 1-octanol comparing $\mathrm{Ru} / \mathrm{AC}$ to $\mathrm{AuRu} / \mathrm{AC}$. The test was first performed by filtering the catalyst and reusing it without any further treatment for the successive run (Table 4).

Both $\mathrm{Ru} / \mathrm{AC}$ and $\mathrm{AuRu} / \mathrm{AC}$ catalysts showed a consistent drop of activity in the second run. According to the literature, deactivation phenomena in alcohol oxidation could be mainly attributed to the leaching of the metal species, passivation of the metal by oxygen or by blockage of the active sites by irreversible adsorbed molecules [1,2]. To explore the possibility of blocked active sites as possible cause of the catalyst deactivation, used $\mathrm{Ru} / \mathrm{AC}$ and $\mathrm{AuRu} / \mathrm{AC}$ were then thoroughly washed with the solvent (toluene) at $100{ }^{\circ} \mathrm{C}$ and then recycled. The washing treatment was not beneficial in the case of $\mathrm{Ru} / \mathrm{AC}$ whereas in the case of AuRu/AC the initial activity was almost restored ( $58 \%$ of conversion instead $66 \%$ of the fresh catalyst) (Table 4).

These results clearly indicate that, in the case of the bimetal-

Table 4

Recycling test in 1-octanol oxidation using $\mathrm{Ru} / \mathrm{AC}$ and $\mathrm{AuRu} / \mathrm{AC}$.

\begin{tabular}{lccc}
\hline Catalyst & Treatment & $\begin{array}{c}\text { Conversion (\%) } \\
\text { after } 12 \mathrm{~h}\end{array}$ & $\begin{array}{c}\text { Selectivity } \\
\text { Aldehyde }\end{array}$ \\
\hline $\mathrm{Ru} / \mathrm{AC}$ & Fresh catalyst & 55 & $>99$ \\
& none & 10 & $>99$ \\
& washing & 15 & $>99$ \\
$\mathrm{AuRu} / \mathrm{AC}$ & Reduced by $\mathrm{H}_{2}$ at $300^{\circ} \mathrm{C}$ & 51 & $>99$ \\
& Fresh catalyst & 66 & $>99$ \\
& none & 25 & $>99$ \\
& washing & 58 & $>99$ \\
& Reduced by $\mathrm{H}_{2}$ at $300^{\circ} \mathrm{C}$ & 62 & $>99$ \\
\hline
\end{tabular}

Reaction conditions: $0.6 \mathrm{~mol} / \mathrm{L}$ in toluene, metal/alcohol ratio $1 / 100$ (mol/mol), $T=100{ }^{\circ} \mathrm{C}, p\left(\mathrm{O}_{2}\right)=200 \mathrm{kPa}$.

a Selectivity after $12 \mathrm{~h}$. 
lic catalyst, the main reason of the deactivation can be attributed to the irreversible adsorption of the products. A treatment with $\mathrm{H}_{2}$ at high temperature $\left(300{ }^{\circ} \mathrm{C}, 3 \mathrm{~h}\right)$ was performed in order to reduce the possible oxidized species. After the reduction treatment, also the activity of $\mathrm{Ru} / \mathrm{AC}$ was almost restored (51\% of conversion instead of $55 \%$ of the fresh catalyst). Therefore, the tests evidenced two different reasons for the deactivation of $\mathrm{Ru} / \mathrm{AC}$ and $\mathrm{AuRu} / \mathrm{AC}$. In the case of the monometallic catalyst, both overoxidation by $\mathrm{O}_{2}$ and deactivation by adsorbed species probably occur, whereas in AuRu/AC only deactivation due to irreversible adsorption is observed. The improvement of catalyst resistance obtained by gold addition could be then ascribed to the beneficial effect of gold addition against $\mathrm{Ru}$ overoxidation. This finding is in agreement with the related effect already observed for $\mathrm{Au}$ addition to $\mathrm{Pd}$ and $\mathrm{Pt}$ catalysts in alcohol and polyol oxidations $[11,12]$.

\section{Conclusions}

Carbon supported $\mathrm{Ru}$ and $\mathrm{Pt}$ based catalysts have been tested for the oxidation of 1-octanol (C8), 1-decanol (C10), and 1-dodecanol (C12) in the presence of molecular oxygen and toluene as the solvent. The activity of the catalysts seems to be influenced by the length of the aliphatic chain being C8 $>$ C10 $>$ C12. Strong deactivation phenomena have been observed, possibly due to the over-oxidation of the metal and the irreversible adsorption of the products on the active sites. The restoring of $\mathrm{AuRu} / \mathrm{AC}$ catalyst activity by simply washing with the solvent evidenced that in this case deactivation phenomena can be mainly ascribed to strongly adsorbed species. On the contrary, $\mathrm{Ru} / \mathrm{AC}$ needs an additional high temperature reduction treatment to restore the initial activity, highlighting the beneficial effect of $\mathrm{Au}$ in maintaining $\mathrm{Ru}$ in the metallic state. In term of selectivity, Ru/AC and AuRu/AC showed very high selectivity to aldehyde (>95\%) whereas Pt/AC promotes the over-oxidation to acid and AuPt/AC the formation of the ester. When dioxane instead of toluene was used as solvent, a detrimental effect in term of activity and selectivity was observed. Moreover, the addition of water to dioxane speeds up the reac- tion rate in all cases. This positive effect in the reaction rate is better evidenced with $\mathrm{Pt}$ based catalysts than on $\mathrm{Ru}$ ones but concomitantly with the decrease in aldehyde selectivity an increase to the acid selectivity is observed.

\section{Acknowledgments}

TEM characterisation was carried out in KIT and sponsored by Karlsruhe Nano Micro Facility (KNMF).

\section{References}

[1] Besson M, Gallezot P. Catal Today, 2000, 57: 127

[2] Mallat T, Baiker A. Chem Rev, 2004, 104: 3037

[3] Dimitratos N, Lopez-Sanchez J A, Hutchings G J. Chem Sci, 2012, 3: 20

[4] Davis S E, Ide M S, Davis R J. Green Chemistry, 2013, 15: 17

[5] Cortés Corberán V, González-Pérez M E, Martínez-González S, Gómez-Avilés A. Appl Catal A, 2014, 474: 211

[6] Villa A, Chan-Thaw C E, Veith G M, More K L, Ferri D, Prati L. ChemCatChem, 2011, 3: 1612

[7] Ishida T, Ogihara Y, Ohashi H, Akita T, Honma T, Oji H, Haruta M. ChemSusChem, 2012, 5: 2243

[8] Shi Y, Yang H, Zhao X, Cao T, Chen J, Zhu W, Yu Y, Hou Z. Catal Commun, 2012, 18: 142

[9] Martínez-González S, Gómez-Avilés A, Martynyuk 0, Pestryakov A, Bogdanchikova N, Cortés Corberán V. Catal Today, 2014, 227: 65

[10] Anderson R, Griffin K, Johnston P, Alsters P L. Adv Synth Catal, 2003, 345: 517

[11] Dimitratos N, Villa A, Wang D, Porta F, Su D, Prati L. J Catal, 2006, 244: 113

[12] Prati L, Villa A, Campione C, Spontoni P. Topics Catal, 2007, 44: 319

[13] Frassoldati A, Pinel C, Besson M. Catal Today, 2011, 173: 81

[14] Jenzer G, Schneider M S, Wandeler R, Mallat T, Baiker A. J Catal, 2001, 199: 141

[15] Yamaguchi K, Mori K, Mizugaki T, Ebitani K, Kaneda K. J Am Chem Soc, 2000, 122: 7144

[16] Opre Z, Grunwaldt J D, Maciejewski M, Ferri D, Mallat T, Baiker A.J Catal, 2005, 230: 406

[17] Yang X, Wang X, Qiu J. Appl Catal A, 2010, 382: 131

\section{Graphical Abstract}

Chin. J. Catal., 2014, 35: 945-951 doi: 10.1016/S1872-2067(14)60101-7

\section{Fragrances by selective oxidation of long-chain alcohols}

Alberto Villa, Carine E-Chan-Thaw, Marco Schiavoni, Sebastiano Campisi, Di Wang, Laura Prati* Milan University, Italy;

Institute of Nanotechnology and Karlsruhe Nano Micro Facility (KNMF), Karlsruhe Institute of Technology, Germany

AuRu/AC showed good durability and selectivity to the corresponding aldehyde $(>95 \%)$ in long chain alcohol oxidation making these catalysts promising for fragrances manufacturing.

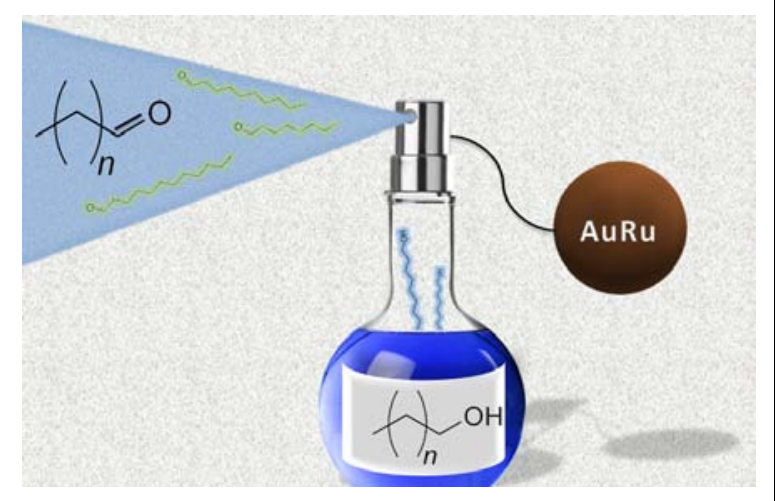


[18] Prati L, Porta F, Wang D, Villa A. Catal Sci Technol, 2011, 1: 1624

[19] Gopiraman M, Babu S G, Khatri Z, Kai W, Kim Y A, Endo M, Karvembu R, Kim I S. J Phys Chem C, 2013, 117: 23582

[20] Mori S, Takubo M, Makida K, Yanase T, Aoyagi S, Maegawa T, Monguchi Y, Sajiki H. Chem Commun, 2009: 5159

[21] Musawir M, Davey P, Kelly G, Kozhevnikov I V. Chem Commun, 2003: 1414
[22] Mori K, Kanai S, Hara T, Mizugaki T, Ebitani K, Jitsukawa K, Kaneda K. Chem Mater, 2007, 19: 1249

[23] Prati L, Martra G. Gold Bull, 1999, 32: 96

[24] Prati L, Villa A. Acc Chem Res, 2014, 47: 855

[25] Brett G L, Miedziak P J, Dimitratos N, Lopez-Sanchez J A, Dummer N F, Tiruvalam R, Kiely C J, Knight D W, Taylor S H, Morgan D J, Carley A F, Hutchings G J. Catal Sci Technol, 2012, 2: 97 